\title{
The Transformative Power of Urbanism. The Urban Age Conference, Venice Biennale (July 2016)
}

\section{Brunella Angeli}

\begin{abstract}
As the world population is increasing at unprecedented rates and wastelands are extending at a variety of new scale and in various spaces organizing the sprawling landscape, the line between formal and informal settings, God's eye view planning walled off from the outside world and temporary structures seems to intensify. There is an urgency to reverse such inefficient growth with its consequent inhuman conditions and better plan world's cities by means of urbanization. The Urban Age "Shaping Cities" Conference at the Venice Biennale (July 14-15, 2016) with the exhibition Conflicts of an Urban Age explored the connections among the political, economic and social city with the scale of its physical and urban form. Addressing themes such as expansion, redevelopment, adaption and confronting speakers and urban solutions from different backgrounds, the conference questioned the role of planning in the definition of more inclusive, safe, resilient and sustainable cities. The theme reconnects to Habitat III, the UN global cities summit set for Quito, Ecuador, in October 2016 implementing the New Urban Agenda for the world's rapidly urbanizing areas.
\end{abstract}

Keywords: Habitat III, New Urban Agenda, sustainability, development, just city

By the year 2050 the world will double its rate of urbanization and twothird of the world's projected population of nearly 10 billion are expected to move to urban centers, even though cities today only cover $0.5 \%$ of 
the world's total land area. This extraordinary process of urbanization that will take place mainly in the developing world - will not only produce wastelands as cities extend and exurban nodes absorb the countryside, but increasingly sprawl slums with little or no access to basic services, threaten climate conditions, ecosystems and food security. It is clear that progressing at these speed, even the fastest-growing cities outside of the western world are grossly unprepared. While land consumption is already being considered by institutions, municipalities, policymakers and the public opinion, the future global conditions equally require a rethinking and new understanding of the quality of urban life in terms of social, rather than financial transactions. This entails connecting the political, economic and social city with its physical form and the scale of its urban growth. Urban Age "Shaping Cities," $16^{\text {th }}$ conference by the LSE Cities center at the London School of Economics and the Deutsche Bank's Alfred Herrhausen Gesellschaft, held in Venice on July 14-16, 2016, explored these connections between the physical and the social world of cities. Introduced by Ricky Burdett (LSE Cities) and Paolo Baratta (La Biennale di Venezia), the conference was organized across two days, six sessions, featuring over 40 speakers, including mayors, planners, architects, academics and commentators from 25 cities. Namely, Urban Age also sets in the context of two major events taking place in 2016. The first is the Reporting from the Front exhibition for the $15^{\text {th }}$ Biennale of Architecture curated by Alejandro Aravena, Chilean architect and co-founder of ELEMENTAL. The "Fronts" of the show are intended as the frontiers or challenges faced in the global world: the potential of materials and their recycle, social housing, reinterpretation of traditional building techniques and urban regeneration. Along these lines, the conference reconnects to the exhibition exploring how design ingenuity can react efficiently to inequalities, segregation and poor living conditions. The second event is Habitat III, the United Nation Conference on Housing and Sustainable Urban Development that will take place in Quito, Ecuador, on October 17-20, 2016. Held every twenty years, UN-Habitat's aim is to bridge design and politics in cities by shaping policy on the social, political and environmental future of human settlements. The sense of urgency is evident for Quito 2016. While Vancouver 1976 (Habitat I) and Instanbul 1996 (Habitat II) only outlined the mission for improving the future growth of the world's cities without specifically engaging with urban and environmental sustainability, this year's focus will be on planning and spatial design as a discriminating factor in making cities more livable, inclusive and sustainable.

Part of the Urban Age Program and jointly organized by LSE Cities and the Biennale di Venezia, the exhibition Conflicts of an Urban Age in the Sale d'Armi of the Arsenale explores patterns of urban growth between 1990 and 2015 documenting the transformation of fishing villages into megacities and asking how 5 billion urban dwellers can be accommodated 


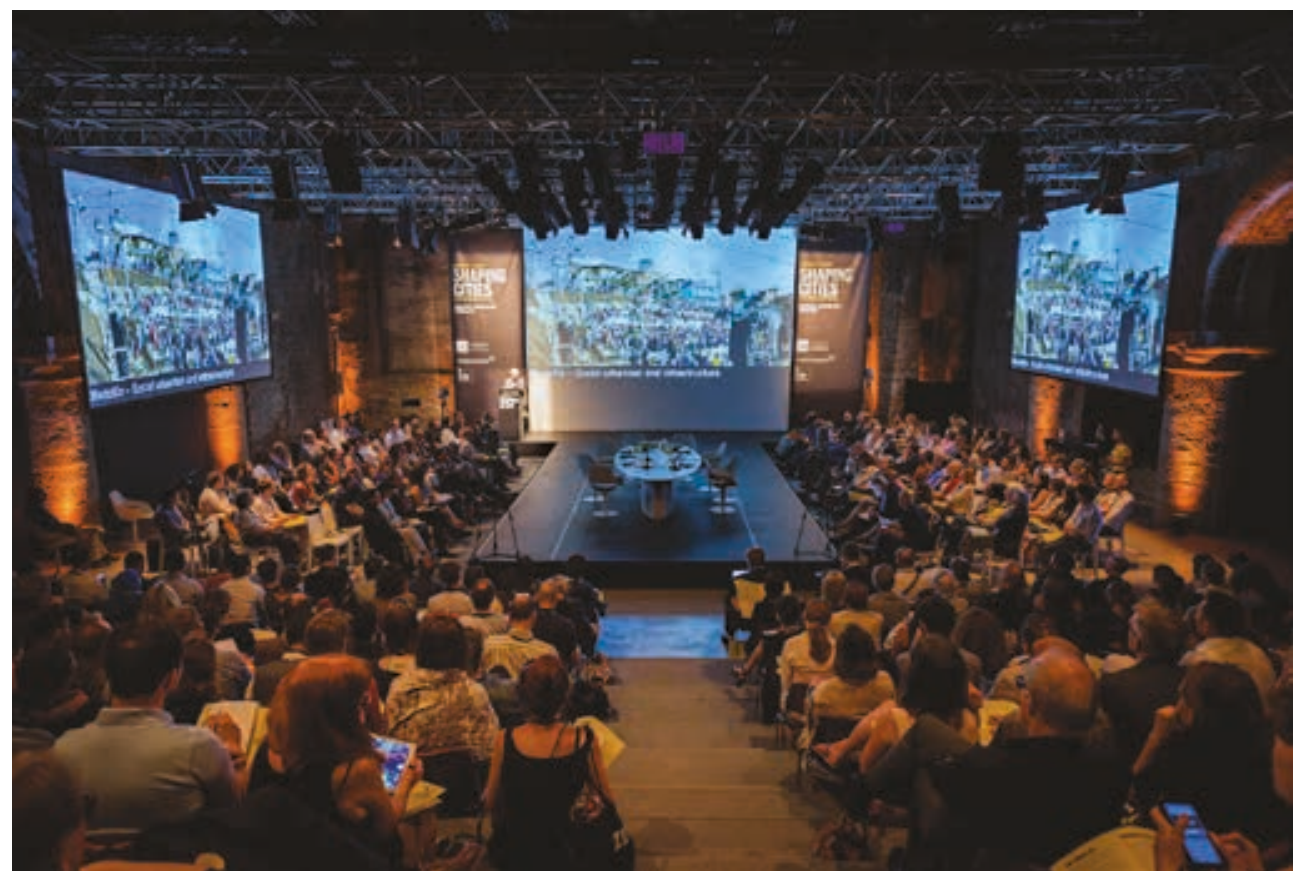

by 2030. Comparing case study cities such as Shanghai, Addis Ababa, London, Istanbul, São Paulo, Mexico City, Mumbai and more through film-based animations offering statistics and analysis of spatial, social and environmental data, the exhibition provides an in-depth understanding of the unprecedented speed and scale of this urban transformation.

In the fascinating setting of the Teatro alle Tese, the warehouses where the sails were stretched in the sixteenth century and made up of four buildings connected by large arches, the first session addressed the question of the ownership of the city. Ada Colau, the recently elected Mayor of Barcelona through the grassroots movement Barcelona en Comu, focused her speech on the right to the city for citizens. Through her own experience as an activist in the "Platform for People Affected by Mortgages," she described how emotions of civic despair had been transformed into proposal for urban actions therefore claiming for a new "municipalism" based on citizens empowerment, social cohesion, ecological responsibility and a new negotiation between public and private sectors. Fiercely set through the first intervention, the panel continued in the same intense feel. Drawing from Saskia Sassen's definition of the city as "a complex and incomplete system" which cannot be reduced to corporate sectors, she claimed that "cityness" today cannot be "raising density," but inventing new means to secure space and a new housing market that don't destroy the complexity and incompleteness of city dynamics. Arguing that public ownership does not guarantee public good, Paris Deputy Mayor Jean-Louis Missika discussed the need to target private urban projects to generate projects of public general interest. 
Only through collaborative methods the commons can be given back to citizens, he added. During the following panel discussion, Ed Glaeser (Harvard) argued that common spaces, such as the street, do not need to be just defined but more precisely defended. For example, the problem with mega-projects developed by transnational property markets is not in their size but in the users they are devoted to - not modest people of modest means - that make the city less accessible. Anaclaudia Rossbach (Cities Alliance) pointed out how many global cities of the North and South face similar problems but they do not have the capacity to solve them alone, therefore marking the need of networks of cities. Yolande Barnes (Savills Real Estate) recalled that it is an old common habit to bring people to suburbia to disempower them, and this model becomes more controversial today because "there is not enough land to go around." During the following discussion, a number of questions were raised: whether it is possible to increase density without increasing costs, and whether cities today have more or less power. From the first session clearly emerged the need to lead more productive consultations between cities and their regions or states in terms of economic, housing and migratory policies and to develop possible alliances among cities sharing the same problems. A more precise idea of high density alternatives that differ from both Los Angeles and Hong Kong as a model for growth was only sketched in the final lines and left as an invitation for the next speakers.

The second session of Day One, "Expansion of Redevelopment," confronted the spatial consequences of the urban form and its planning over production and social inclusion. Joan Clos, Executive Director of UN-Habitat, opened the session describing how the large majority of new urbanization is taking place in the developing world. If urban population is exploding - he argued - urban consumption is growing even more. Left without guidance, this trend is destined to develop unproductive urbanization, while in setting the UN New Urban Agenda is gathering principles such as economies of agglomeration as a means to contrast inefficient urban sprawl. Mark Swilling (Stellenbosh University) showcased the implications of extreme urban expansion in South Africa. Shlomo Angel (New York University) critically provoked the session claiming that expansion and redevelopment are not a choice. Going further, he pointed out that population and income grow hand in hand as people getting richer tend to consume more and concluded that the current housing problem is actually a land problem. In the following panel discussion Enrique Peñalosa, mayor of Bogotá, Jennifer Musisi (Kampala Capital City Authority) and Serge Salat (Urban Morphology and Complex Systems Institute) discussed on the theme. While Peñalosa outlined the Bogotá case whose extremely high density needs to be mediated by actions of recycle and reuse thus prescribing a mix of expansion and redevelopment, Salat focused on the quality of the development in order to provide value. Like Venice, which was one of the most powerful cities 


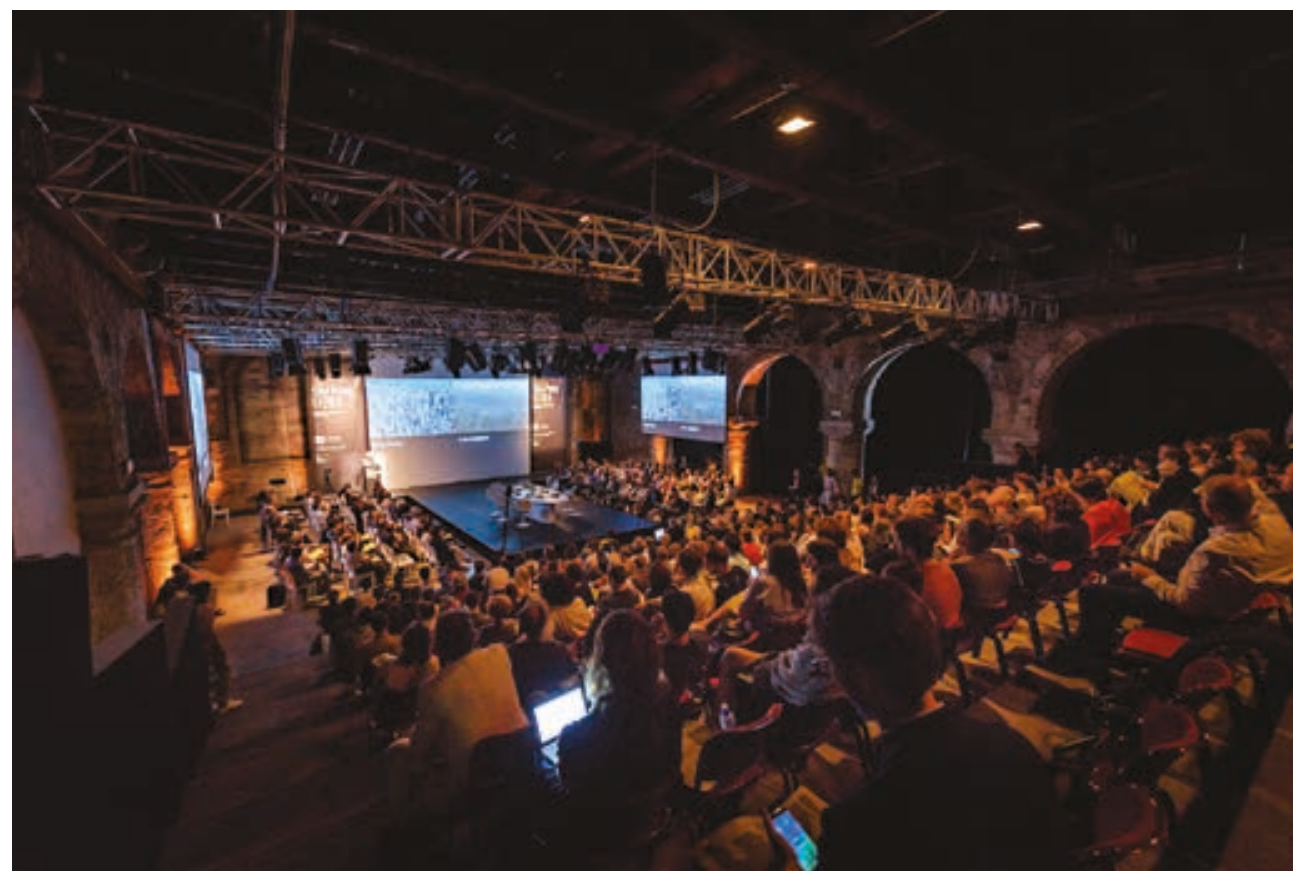

in the Medieval Mediterranean area, or Singapore, which was one of the poorest cities of Asia only fifty years ago, the most successful cities in the world are able to plan flexibility. If the idea that planners, municipal and national authorities should confront and provide guidelines to steer urban growth was agreed upon by the various panelists, the most challenging question emerged during the second session is where should we grow in terms of urban expansions. Also, specific examples of the ways in which urban forms can change course for the environment were suggested in order to make room for the new within the already built environment.

The last session of Day One was titled "Adaption and Social Integration". Richard Sennet (LSE, NYU) framed his intervention around his definition of the "open city," one with poor edges, synchronous space and incomplete buildings. He observed how the concept of identity is not fixed but evolving along with changes in the physical environment; in fact, the ethnic, political, financial diversities of urban residents are the stimuli that bring us to live in cities. Nigh impossible to avoid reference to the recent Brexit referendum, Sennet commented that the greatness of cities is also that people tolerate and feel comfortable living with the unfamiliar, diverse and complex, something more demanding to achieve in the provinces. Presenting her work on migrant streets across the UK, Suzanne Hall (LSE) illustrated how a super diverse nationality presence on urban fronts can make a street like a small factory creating a resilient economy and an increasingly hybrid social network tool where migrants reside, work and develop highly skilled jobs. AbdouMaliq Simone (Max Planck Institute for Religious and Ethnic Diversity) presented his work on "feral urbanism" and questioned the notion 
of the household arguing that most people live in a much larger and pluralized condition than the traditional sense that policymakers confer to it. The discussion on the social fabric of cities was further stimulated by Jean Louis Missika affirming that urban planning is only part of the answer to build social relationships among citizens and communities. Rahul Mehrotra (Harvard) put emphasis on the social roles played by sacred spaces in urban and suburban realms, and that the meanings that we tend to attribute to spaces are constantly shifting. In understanding the social and physical viability of traditional urban planning, all speakers concentrated on the recognition of new temporal and permeable boundaries of the street that transcend the ordinary concept of neighborhood, which is conversely carrier of fixed individual, emotional and geographical implications. While sprawling is certainly no longer an option, the margins of expansion must be combined between political and real interests for the future of cities.

Day Two focused more directly on architecture and design. Alejandro Aravena (ELEMENTAL) opened the first session "Urban Solution: What Role for Architecture?" connecting the Urban Age conference to the $15^{\text {th }}$ Venice Biennale themes, that explore how design ingenuity can be harnessed to respond to everyday social and environmental battles. Claiming that the city owns a critical mass and that we will still meet each other within city boundaries, through his optimistic view he declared that "the more people come to the city, the better." Therefore, cities can be alternative paths to solve inequalities, redistribution and can work as a vehicle for development. Also, he mentioned how current environmental maps correspond more frequently to the security threat that ties acts of terrorism to climate change. Oftentimes, natural resources evolve into causes for civil conflicts among locals or nations, absorbing incursions, decay and contaminations and turning fertile regions into highly fragile territories. Greeting the environment as no longer an "hippy-romantic" theme, Aravena also underscored that we need to create knowledge that uses different technology for $60 \%$ less energy. Rahul Mehrotra, illustrating his research and exhibition at the Biennale Ephemeral Urbanism, cities in constant flux on the religious festival of Kumbh Mela, framed his speech on the need for contemporary cities to think in terms of temporaneity rather than permanence. As a temporary pilgrimage city of two months being informally built on the delta of the Ganges and Yamuna sacred rivers every 12 years, Kumbh Mela challenges our notion of urban design as huge and highly influential projects which indeed turn as disengagement from reality. Our baggage as western citizens is to take permanence as default both in design and government, while we need to consider that the vast majority of design worldwide is informal and that nonpermanent configurations of the urban are a legitimate and productive category within the discourse on cities. Kunlé Adeyemi (NLE), presenting his floating school for Makoko in Lagos (Nigeria) to make fragile coastal areas more resilient to environmental threats, enlarged the discourse on the social impact of impermanent architecture. 


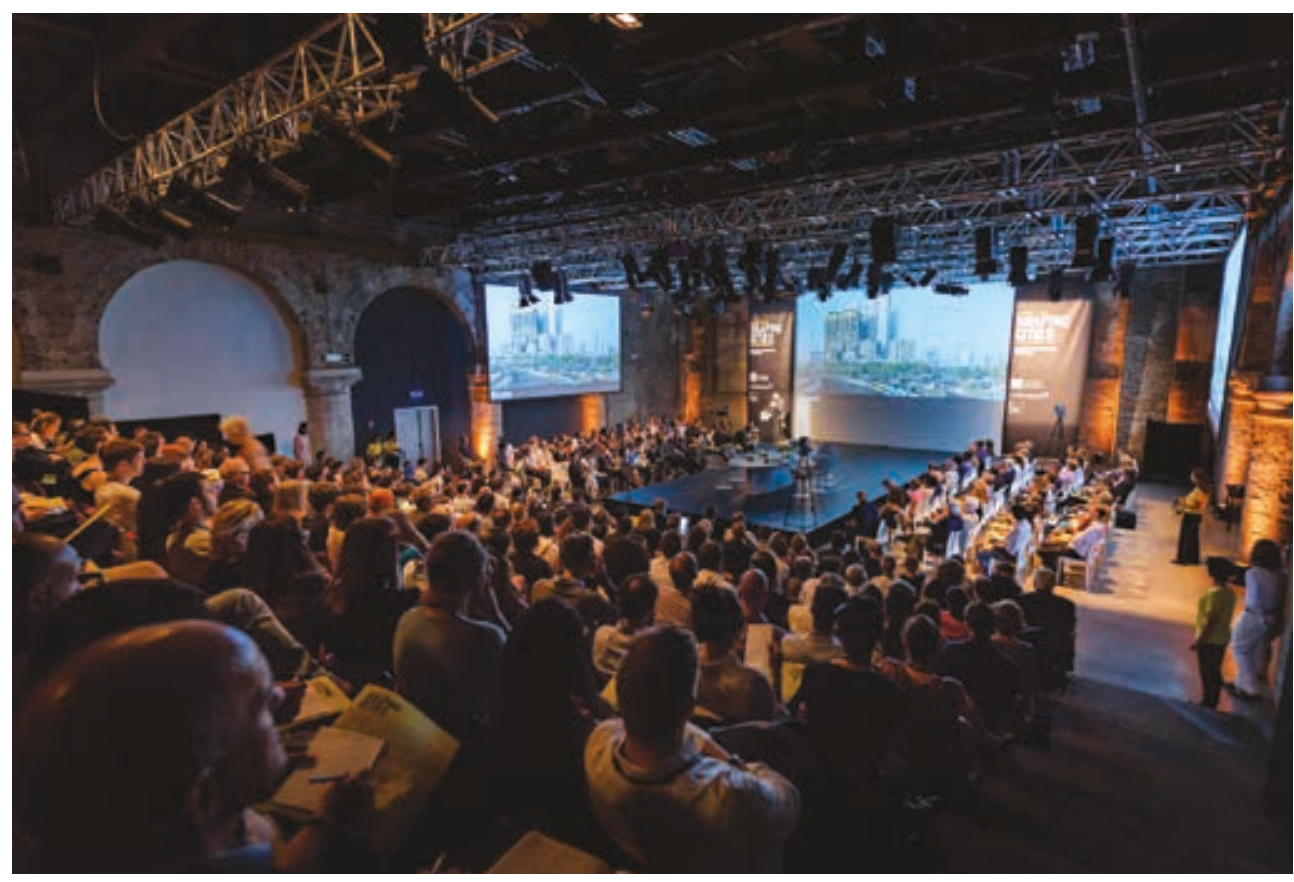

The double-session "Scales of Intervention" was divided in "Solutions from Below" and "Solutions from Above," featuring speakers whose experience was either on small-scale, community-led urban projects or on top-down corporate developments. Julia King (LSE) introduced her work on sanitation in Delhi: while building more than 300 households, local communities gained specific knowledge that developed awareness and assertions on their own housing standards. Rozana Montiel (Rozana Montiel Estudio de Arquitectura) presented her work on Mexico City focusing on the necessity of creating a replicable process rather than an architectural product, while Ilan Shoat (Mayor of Safed, Israel) presented the experience of a Medical School as a game changer and economic engine for the city. The debate was animated by Jo Noero (Noero Architects) arguing that architects should never forget to think and act as such as they are paid by people to "make things work for them" therefore the social value of architecture is already embedded in its scope and should not be the focus. Amica Dall (Assemble Architects) presented her work on housing regeneration while Sean Anderson (MoMA) discussed the fragility of the refugee camp that, although becoming a city, is often perceived as a shadow city. "Solutions from Above" was opened by Ed Glaeser making the case that more urbanization equals to more growth, supported by analytic data indicating that nations with more cities have increased their GDP between 1960-2010. Kees Christiaanse (KCAP) picked up the debate asking what are the limits of urban design when there are multiple levels projects that reconfigure as new "centralities" for cities. Megaprojects such as La Défense, Canary Wharf or Marina Bay - he continued - are always complementary to slums. José Castillo (a911) dissented from the act of choosing between "top-down" and "bottom-up" as 
a failure in conceptualization (i.e. replicating successful designs elsewhere), process (i.e. how to allocate the resources) and implementation (i.e. putting value in capital instead of implementation). Henk Ovink (Special Envoy for International Water Affairs) presented the US\$60b work after hurricane Sandy and finally Stefano Recalcati (Arup), while describing the requalification of Marghera in Venice and the Docklands in Dublin, described how large-scale interventions cannot be bottom-up. What remains uncertain in the process is whether they positively impact the communities or not, which is anyhow their ultimate goal.

The last session of the conference, "Shaping the New Urban Agenda," addressed more specifically the cases and issues that will inform Habitat III in Quito next October 17-20, 2016. There was a lot on the plate as the New Urban Agenda aims to shape the future of urban policies over the next couple of decades. Before we incur greater costs, Peñalosa advised, we should keep Latin America as a "what not to do" reminder, depicting an urban environment where highways are poisonous rivers and the surroundings and living conditions are pedestrian-unfriendly. While Jennifer Musisi clearly articulated the need of urbanity for Africa illustrating Kampala's governance challenges, Jagan Shah (National Institute of Urban Affairs, New Delhi, India) expressed the need of public-private partnerships and effective urban governance. During the lively final discussion the notion of the "right to the city" was debated in terms of diversity, spatial access and sustainable urban development. While Ilaria Boniburini (University of Witwatersrand, Johannesburg) defended the position that the smallest spatial indications should be given within urban agendas, it was also admitted the general reluctance of academia in producing physical models from which to deduct local solutions to general problems. Ricky Burdett finally raised the issue of language of the agendas that will be produced out of Habitat III doubting that they will do justice to connecting spatial and social dimensions. While the tendency is that of using specialist terminology focusing on transportation or economy, our urban agendas need to address social issues of inequalities in terms of spatial visions. Also, the idea that regional and national levels of governance have to overcome frictions and co-operate in order to drive and find solutions was agreed upon by panelists and speakers. Final remarks were left to Joan Clos who argued that in the world there is "too much architecture and too less urbanism." Conversely, urbanization has become today a strategic issue of policy and therefore it is necessary to find a negotiation between the two terrains. He concluded suggesting that innovative proposals of participation that can provide a different spatial layout for our cities could be a beginning to fill the gap.

By gathering these diverse and specific voices, Urban Age was able to arouse the potential for exchange that is needed in the definition of an agenda for the future of cities that takes into account both the morphology 
and the policy-making process. As architects and urban planners are more often the ingenuous executors of developers, governments and politics who are instead agents of huge capital flows, it is now clear that design is a language that needs institutions and cannot entrust other disciplines to take its place. UN-Habitat III hopes to stand just right in this policy: to set an agenda flexible enough where stakeholders would add or simplify structure when needed, to promote any kind of non-profit and institution partnerships, finally to enable dialogs among old and new economies. Under the leadership of Jean Clos, former Barcelona mayor, the summit will gather UN member states, international organizations, stakeholders and planners, hopefully reaching a consensus for the New Urban Agenda to get approved. Alas, this is part of the challenge as urban policies refer to cities rather than nations, and there are executive levels of organization where agreements can be delayed. After halted initial negotiations in July, an agreed draft of the Agenda has been signed at the Informal Intergovernmental Meeting in New York in September 2016 where it was decided the summit's focus on "implementation."

In twentieth century Global North, planning became the basis of every civilized city, yet many of the most successful western cities have fallen short in dealing with the most recent critical transformations: mass immigration, financial crisis, the breakdown of traditional industry, globalization and more. Part of the issue is that planning had to respond to a commercial agenda, or even when it regarded social concerns - like in East Germany - it was allowed to lie unused. On the other hand, informal settlements have been the ingenious, inventive and versatile answer of the Global South where most of the world's urban population today reside. The good news is that each can learn something from the other. The contrast between the staggering variety, intelligence and speed in responding to successive crises and changing conditions embodied in the unplanned city may work as an inspiration for the atomization, lack of responsiveness and large waste of the wealthy city. This transfer of knowledge, however, remains difficult. Many communities feel too comfortable in their own condition to welcome a change while others don't have the models or the experience to activate public space; also, the static and inflexible laws that rule the city of the Global North seems to repress this mutual exchange. The Urban Age conference brought precisely to the forum questions on the idea of the city. What is it for? Who is it for? Can we use the norms and scope of the informal to start redefine anew urban conditions and take humanity back at the heart of the city? By now, we can draw a parallel with the Reporting from the Front image-manifesto using the metaphor of the ladder as a tool that allows us to gain a new perspective and share the knowledge with those standing on the ground. The exchange provides an understanding that against scarcity - which can be due to lack of cohesion rather than resources - we can use inventiveness. Similarly, against abundance we can use pertinence as a way to play our part in redesigning our novel idea of the city. 


\section{Credits}

All figures are from the Urban Age Conference, "Shaping Cities", July 14-15, 2016. Jointly organized by LSE Cities and the Alfred Herrhausen Gesellschaft, Deutsche Bank, and hosted by La Biennale di Venezia, Venice (Italy). Photos by Andrea Avezzù. (c) Courtesy of La Biennale di Venezia.

Brunella Angeli holds a MArch (2008), and a PhD in Architectural History and Theory (2016), from the Politecnico di Milano. She has been a Visiting Scholar at the University of California, Berkeley during her dissertation research, exploring great events' urban models. She has co-authored a book on Italian post-modern architecture, L'avventura del progetto (2012), and her writings on urban design and the architecture of the city have been published in several international journals. She has worked on exhibitions at the MAXXI Museum in Rome, Palazzo Té in Mantua (Italy) and at the Venice Biennale. For the 201617 academic year Brunella is a Lecturer at UC Davis, California, and, since Fall 2016, she is an Editor for The Plan Journal. E-mail: brunella.angeli@theplanjournal.com. 